\title{
Editorial: Sustainable Energy Production and Consumption: System Accounting, Integrated Management, Policy Responses
}

\author{
Benjamin C. McLellan ${ }^{1}$, Xu Tang ${ }^{2 \star}$ and Jing Meng ${ }^{3}$ \\ ${ }^{1}$ Graduate School of Energy Science, Kyoto University, Kyoto, Japan, ${ }^{2}$ School of Economics and Management, China University \\ of Petroleum, Beijing, China, ${ }^{3}$ The Bartlett School of Sustainable Construction, Faculty of the Built Environment, University College \\ London, London, United Kingdom
}

Keywords: sustainability, energy, management, trade, transitions

Editorial on the Research Topic

Sustainable Energy Production and Consumption: System Accounting, Integrated Management, Policy Responses

\section{INTRODUCTION}

OPEN ACCESS

Edited and reviewed by: Simone Bastianoni,

University of Siena, Italy

${ }^{*}$ Correspondence: Xu Tang

tangxu@cup.edu.cn

Specialty section: This article was submitted to Sustainable Energy Systems and Policies,

a section of the journal Frontiers in Energy Research

Received: 22 September 2021

Accepted: 05 October 2021

Published: 03 November 2021

Citation:

McLellan BC, Tang $X$ and Meng $J$ (2021) Editorial: Sustainable Energy Production and Consumption: System Accounting, Integrated Management,

Policy Responses.

Front. Energy Res. 9:781252.

doi: 10.3389/fenrg.2021.781252
This Research Topic was proposed with the intent to: 1) share and catalog experiences of how to conduct system accounting for energy production and consumption from different perspectives, 2) to promote a deeper understanding of the resource nexus by considering integrated management of "Energy+" systems, and 3) to encourage critical discussion of policy responses for sustainable energy production and consumption, to connect academic research and practical management. The eventual submissions covered a range of themes, although the Energy+ (or Energy-X-Nexus) approach was less covered. Energy and the potential economic opportunities for reducing greenhouse gas emissions were considered at a variety of scales-national, provincial, sectoral, company-and using various alternative techniques.

\section{ARTICLES}

Nine papers have been published under this topic, covering a broad range of areas in the field, but with an overall tendency towards examining macro-economic and sectoral environmental and economic performance, and the influence of factors such as innovation, investment, and subsidization.

Industrial environmental efficiency was focused on by (Sun et al.), who considered overall environmental efficiency as being composed of two serial elements-economic development and environmental governance. They evaluated the two elements, considering the effects of a variety of indicators, including urbanization, and demonstrated that the economic development focus was in general more related to industrial environmental efficiency.

Similarly, the study by (Xie et al.) examined the improvement of environmental performance in resource-based cities in China, demonstrating that the introduction of technology from external sources was not as effective as indigenous technological innovation in improving green 
transformation. This study suggests that direct research and development investment is an effective tool in achieving the desired outcomes. The effect of research and development investment was also indicated as important for regions to improve total factor coal productivity (Wang et al.). The positive impact of government subsidies on technology innovation up to a certain threshold was demonstrated by (Wang et al.).

The influence and efficiency in value creation for online platform-based companies in transitioning towards more sustainable options was examined by (Xie et al.). This case study on the energy sector tried to model the mechanism of this choice in transition.

Divisia techniques were used to consider sub-sectoral influences and opportunities for improvement in emissions, indicating the strength of the energy structure for Xinjiang Production and Construction Corps (Wang et al.). While (Zeng et al.) considered provincial level opportunities for reducing carbon emissions from electricity production, finding a cooperative model in which provinces could combine or trade efforts in emissions reduction, to be more effective and fair than each province being forced to seek emissions reductions internally.

Energy embodied in trade was analyzed for China at the sectoral and international level by (Zhang et al.), using trade in value-added methods. They show a difference between the sectors that produce the most economic value and those that have the highest embodied energy, thus indicating a potential to create mutual benefit by restructuring the embodied energy export structure.
On a very different topic, (Wei et al.) developed methods to diagnose the performance of hydraulic turbines.

\section{CONCLUDING REMARKS}

The editors hope that the published papers will interest the readers and initiate some interesting and informative discussion in the open review process.

\section{AUTHOR CONTRIBUTIONS}

The editorial was drafted by BM, checked by XT and JM.

Conflict of Interest: The authors declare that the research was conducted in the absence of any commercial or financial relationships that could be construed as a potential conflict of interest.

Publisher's Note: All claims expressed in this article are solely those of the authors and do not necessarily represent those of their affiliated organizations, or those of the publisher, the editors and the reviewers. Any product that may be evaluated in this article, or claim that may be made by its manufacturer, is not guaranteed or endorsed by the publisher.

Copyright (C) 2021 McLellan, Tang and Meng. This is an open-access article distributed under the terms of the Creative Commons Attribution License (CC $B Y)$. The use, distribution or reproduction in other forums is permitted, provided the original author(s) and the copyright owner(s) are credited and that the original publication in this journal is cited, in accordance with accepted academic practice. No use, distribution or reproduction is permitted which does not comply with these terms. 